\title{
Post-earthquake Rainfall-triggered Slope Stability Analysis in the Lushan Area
}

\author{
YANG Zhi-hua',2 e-mail: yangzh@lreis.ac.cn; (iD oooo-ooo2-4372-3431

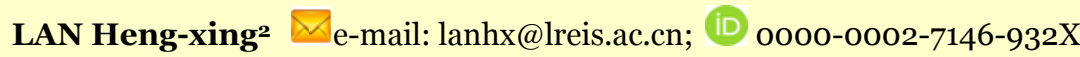 \\ LIU Hong-jiang3 e-mail: hjliu@lreis.ac.cn; (iD) oooo-0oo2-5574-6083 \\ LI Lang-ping² e-mail: lilp@lreis.ac.cn; (iD) oooo-ooo1-6398-3161 \\ WU Yu-ming² e-mail: wuym@lreis.ac.cn; (iD oooo-0oo3-1659-028X \\ MENG Yun-shan² e-mail: mengys@lreis.ac.cn; (iD oooo-ooo1-8562-5445 \\ XU Liang4 e-mail: liangxu28@sina.com; iD oooo-0003-0787-9866 \\ 1 Institute of Geomechanics, Chinese Academy of Geological Sciences, Beijing 100o81, China \\ 2 State Key Laboratory of Resources and Environmental Information System, Institute of Geographic Sciences and Natural \\ Resources Research, Chinese Academy of Sciences, Beijing 100101, China \\ 3 Catastrophe Risk Research Center, Yunnan University of Finance and Economics, Kunming 650221, China \\ 4 General Geo-environmental Monitoring Station of Sichuan Province, Chengdu 610o81, China
}

Citation: Yang, ZH, Lan HX, Liu HJ, et al. (2015) Post-earthquake rainfall-triggered slope stability analysis in the Lushan Area. Journal of Mountain Science 12(1). DOI: 10.1007/s11629-013-2839-6

(C) Science Press and Institute of Mountain Hazards and Environment, CAS and Springer-Verlag Berlin Heidelberg 2015

\begin{abstract}
The “4.20" Lushan earthquake in Sichuan province, China has induced a large amount of geological hazards and produced abundant loose materials which are prone to post-earthquake rainfalltriggered landslides. A detailed landslide inventory was acquired through post-earthquake emergent field investigation and high resolution remote sensing interpretation. The rainfall analysis was conducted using historical rainfall records during the period from 1951 to 2010. Results indicate that the average annual rainfall distribution is heterogeneous and the largest average annual rainfall occurs in Yucheng district. The Stability Index MAPping (SINMAP) model was adopted to assess and analyze the postearthquake slope stability under different rainfall scenarios (light rainfall, moderate rainfall, heavy rainfall, and rainstorm). The model parameters were calibrated to reflect the significant influence of strong earthquakes on geological settings. The slope stability maps triggered by different rainfall scenarios were
\end{abstract}

produced at a regional scale. The effect of different rainfall conditions on the slope stability is discussed. The expanding trend of the unstable area was quantitatively assessed with the different critical rainfall intensity. They provide a new insight into the spatial distribution and characteristics of postearthquake rainfall-triggered landslides in the Lushan seismic area. An increase of rainfall intensity results in a significant increase of unstable area. The heterogeneous distribution of slope instability is strongly correlated with the distribution of earthquake intensity in spite of different rainfall conditions. The results suggest that the both seismic intensity and rainfall are two crucial factors for postearthquake slope stability. This study provides important references for landslide prevention and mitigation in the Lushan area after earthquake.

Keywords: Lushan earthquake; Rainfall; Slope stability; SINMAP; DEM

Received: 22 July 2013

Accepted: 31 December 2013 


\section{Introduction}

The catastrophic "4.20" Lushan earthquake with magnitude Ms7.o (Mw6.6, USGS) occurred on April 20, 2013 in Lushan county, Sichuan province, China. The epicenter was located at $103^{\circ} \mathrm{E}$ and $30.3^{\circ} \mathrm{N}$, and the focal depth was $13 \mathrm{~km}$ (China Earthquake Administration 2013; Xu et al. 2013; Chen et al. 2013). The maximum earthquake intensity was 9 degrees, and the area of earthquake-affected regions with earthquake intensity over 6 degrees was about $15,720 \mathrm{~km}^{2}$. More than 2000 aftershocks were monitored, of which 90 aftershocks were greater than magnitude Ms3.o, the greatest of which was magnitude Ms5.4. Focal mechanism analysis shows that this earthquake resulted from the thrust campaign of the southern section (Dachuan-Shuangshi fault) of Longmenshan fault with strike NE-SW and dip NW (Xu et al. 2013). The earthquake has resulted in a large number of casualties (193 killed and 12,211 wounded) and economic loss.

A large number of co-seismic geological hazards have occurred with higher frequency and greater intensity compared with before earthquake. Earthquakes can significantly affect geological conditions, for example making more cracks in rock masses, reducing the integrity of rock masses, and changing the original structure and physical and mechanical properties of rock masses (Miles and Keefer 2009; Vidrih et al. 2001; Cui et al. 2008; Liang et al. 2009). The earthquake played an important role in triggering most of the preexisting and some of the potential geological hazards in earthquake-affected regions. It significantly increased their magnitude and occurrence frequency and finally exacerbated their likelihood and destruction capability. Postearthquake landslide types are mainly rock and soil slides with shallow or moderate thickness. Viscous debris flows with soil material are the dominant type of post-earthquake debris flows. At the same time, the earthquake made many slopes unstable and produced abundant loose sediments and deposits, which are likely to be transformed into landslides or debris flows under subsequent intense rainfall.

Rainfall is one of the most significant triggering factors for landslide occurrences, about $90 \%$ of which coincide with intense rainfall (Lan et al. 2003). Rainfall can not only increase the saturation of rock masses to reduce their shear strength but can also result in increasing pore water pressure and a softer and more lubricated sliding surface, which are extremely unfavorable for slope stability (Simoni et al. 2004; Schulz et al. 2009; Baum et al. 2010; Muntohar and Liao 2010). To account for the effect of rainfall on the slope stabilities, the Stability Index MAPping model (SINMAP) is adopted. It combines the infinite slope stability model and hydrological distribution model based on Digital Elevation Model (DEM), and is implemented on the GIS platform (Pack et al. 1998; Pack et al. 2005). It fully takes into account the crucial impact of rainfall-induced groundwater distribution on landslide occurrences, and effectively solves the uncertainty of model parameters through probabilistic methods (Lan et al. 2003). It is more suitable for shallow landslides such as the dominant landslide type in the Lushan area and has been successfully applied in many studies and regions (Lan et al. 2004; Deb and ElKadi 2009; Terhorst and Kreja 2009; Meisina and Scarabelli 2007).

The severely earthquake-affected regions in Lushan are also highly vulnerable to the rainfalltriggered landslides which pose an inevitable threat to the post-earthquake reconstruction. Based on landslide inventory and historical rainfall records, the post-earthquake slope stability assessment was conducted under different rainfall scenarios (light rainfall, moderate rainfall, heavy rainfall and rainstorm). The associated slope stability distribution maps help understand the spatial distribution and characteristics of post-earthquake rainfall-induced landslides at a regional scale.

\section{Study Area}

The selected study area affected by the Lushan earthquake is located in the middle of Sichuan province, China with longitude $120.27^{\circ}-103.39^{\circ}$ east and latitude $29.48^{\circ}-30.95^{\circ}$ north, which covers about $10,334 \mathrm{~km}^{2}$ (Figure 1). It is also located at the sharp transition zone from the Qinghai-Tibet Plateau to the Sichuan Basin with complex topography and large elevation differences. On the whole, the northwest regions are higher with a maximum elevation of $5293 \mathrm{~m}$, and the 


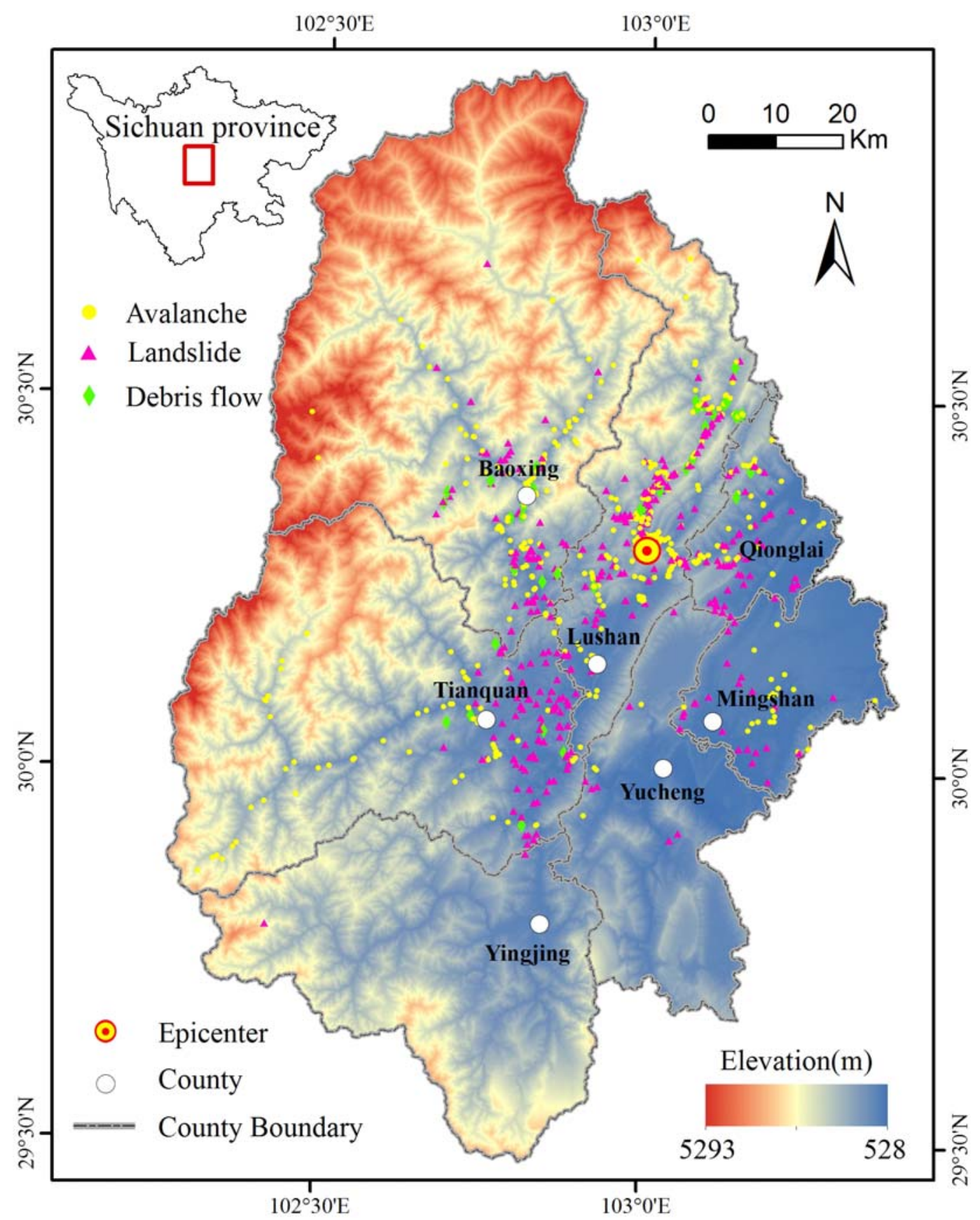

Figure 1 Overview of the study area and the distribution of geo-hazards. The left-top red rectangle indicates the location of the study area.

southeast regions are lower with a minimum elevation of $528 \mathrm{~m}$. This area belongs to the northeast binding site of the Kangdian tectonic belt, Longmenshan tectonic belt and Sichuan Basin, and crosses two tectonic units: the southern section of the Longmenshan tectonic belt and the Sichuan Basin. Folds and faults are predominant geological structures, which are well developed. Affected by Longmenshan tectonic belt with NE orientation, the most regional tectonic structures have $\mathrm{NE}$ orientation, including Baoxing anticlinorium, Lushan syncline, Shuangshi-Dachuan thrust fault.

The main geomorphology types include the fluctuating mountains formed by erosion and denudation and steep-deep valleys. There are a small number of mesas, hills and plains in the southeast of the study area. The population density of western and northern mountainous regions is 
not high, but the resident locations are much dispersed, which brings difficulties for the geological hazards prevention and mitigation. The transport facilities are deficient in mountainous regions, for example there is only one provincial highway across Baoxing county, which can easily cause traffic disruption and delay the process of emergent rescue mission.

\section{Landslide Inventory, Rainfall Conditions and Other Materials}

Accurate landslide inventory is an essential element for a successful hazard assessment. It is the first crucial step during the assessment and analysis of landslide hazard (Deb and El-Kadi 2009; Terhorst and Kreja 2009; Guzzetti et al. 1999; Aleotti and Chowdhury 1999). According to the post-earthquake emergent field investigation conducted by the Ministry of Land and Resources of the People's Republic of China, there were about 840 geo-hazard events (including avalanches, landslides and debris flows) in the study area. In addition, 338 geo-hazard events were observed through the remote sensing interpretation of Unmanned Aerial Vehicle (UAV) images. They are mainly distributed in Baoxing County and many towns near the epicenter. Figure 2 presents the post-earthquake geo-hazard distribution in the urban area of Baoxing County through remote sensing interpretation of UAV images.

The historical geological hazards were also collected, which were mainly developed in valley regions. The valley regions are mainly inhabited areas, where there are intense human engineering and economic activities that result in abundant broken rock masses and loose sediments and deposits. Debris flows often distribute across multiple geomorphological units, and the accumulation regions are generally located in a canyon. Material resource regions of debris flows are sometimes higher than the deposition regions by hundreds of meters. The distribution of earthquake-triggered geological hazards is strongly correlated with earthquake intensity (Zhang et al. 2013). These hazards are not concentrated in valley regions; rather, they are mainly distributed in the regions with earthquake intensity of 7-9 degrees, such as Lushan county, southern Baoxing county,

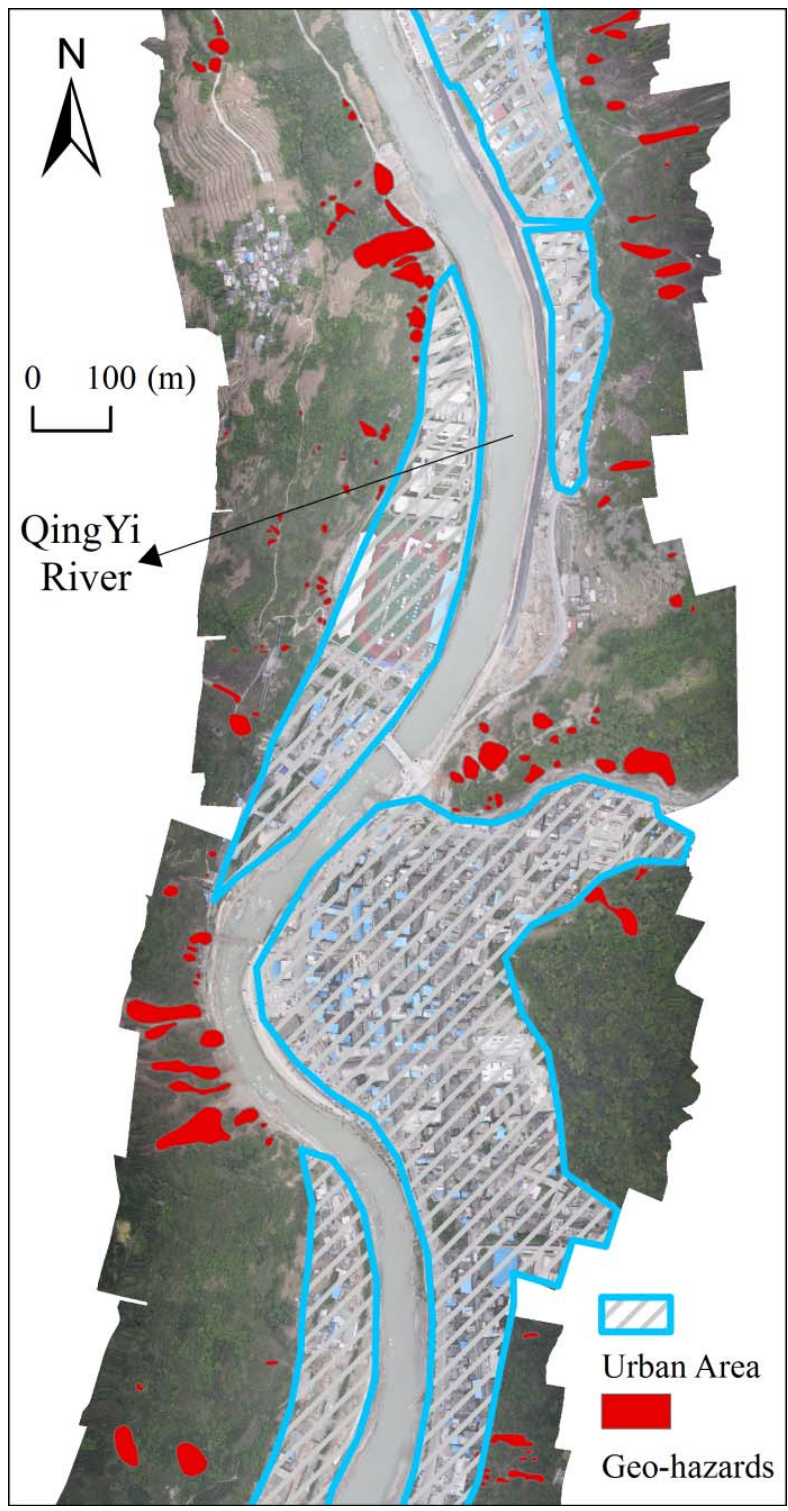

Figure 2 The distribution of post-earthquake geohazards in the urban area of Baoxing county through remote sensing interpretation of Unmanned Aerial Vehicle (UAV) images conducted by the Chengdu University of Technology.

eastern Tianquan county and western Qionglai county.

The DEM was derived from national digitized topographic maps with scale of 1:50,000 and a contour size of $10 \mathrm{~m}$, which were interpolated to create the $20 \mathrm{~m} \times 20 \mathrm{~m}$ raster dataset. Then, this DEM was used to generate the slope angle, slope aspect, flow direction, catchment area and other thematic data. Other necessary data include: the earthquake intensity map derived from China Earthquake Administration, a geological map with 
scale at 1:500,000, a tectonic fault map with scale at 1:2,500,000, a geomorphology map with scale at 1:1,000,000 and a drainage map with scale at 1:50,000. The landslide inventory was stored in a vector dataset and all other thematic data were stored in the raster dataset with spatial resolution of $20 \mathrm{~m} \times 20 \mathrm{~m}$.

The rainfall is abundant in the study area, but its spatial and temporal distribution is nonhomogeneous. During rainy and flood seasons, the rainfall intensity is relatively higher, and the maximum rainfall mainly occurs in July and August. Based on the historical rainfall records (1951a - 2010a) from 21 rainfall monitoring sites and 48 secondary rainfall monitoring sites in the study area and its surrounding regions, the spatial distribution of average annual rainfall (Figure 3) was obtained using the Kriging interpolation method. The analytical results show that the average annual rainfall ranges from $697 \mathrm{~mm} / \mathrm{a}$ to $1612 \mathrm{~mm} / \mathrm{a}$, and the southeast regions (e.g. Yucheng, Mingshan, southern Lushan, eastern Tianquan and Qionglai) have relatively higher rainfall intensity while other regions have relatively lower intensity. The total rainfall is characterized

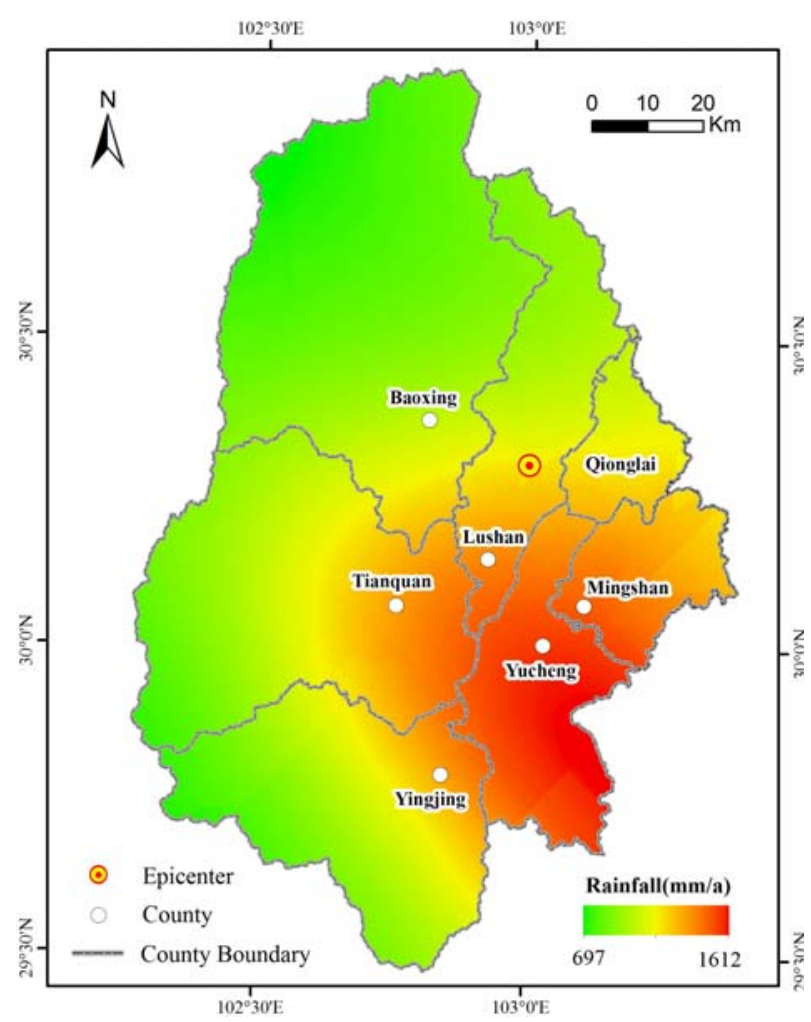

Figure 3 Average annual rainfall (mm/a) derived from the historical rainfall records (1951a - 2010a) using the Kriging interpolation method. by a large number of night rainfall events of short duration and high intensity.

\section{Slope Stability Assessment}

\subsection{Methods}

Based on many previous studies (Montgomery and Dietrich 1994; Dietrich et al. 1995), Pack et al (1998, 2005) established the SINMAP model, which effectively integrates the infinite slope stability model, the DEM-based hydrological distribution model and the GIS platform, and fully takes into account the crucial impact of rainfall, lithology and topography on slope stability. The slope safety factor (FS) (ratio of stabilizing to destabilizing forces) is given by Equation (1), where $C$ is cohesion $(\mathrm{Pa}), \gamma_{s}$ is soil weight $\left(\mathrm{kg} / \mathrm{m}^{3}\right), \gamma_{w}$ is water weight $\left(\mathrm{kg} / \mathrm{m}^{3}\right), \varphi$ is internal friction angle $\left({ }^{\circ}\right)$, and $\theta$ is slope angle $\left(^{\circ}\right), h$ is soil depth $(\mathrm{m})$, and $h_{w}$ is the height of the water table within the soil layer.

$$
\begin{aligned}
F S= & \left\{C / \gamma_{S} h+\left[\gamma_{s}\left(h-h_{w}\right)+\left(\gamma_{s}-\gamma_{w}\right) h_{w}\right]\right. \\
& \cos \theta \tan \varphi\} / \gamma_{s} h \sin \theta
\end{aligned}
$$

Because the model parameters have temporal and spatial uncertainty, it is very difficult to determine exact model parameters. The SINMAP model introduces the concept of slope stability index (SI) and provides a probabilistic method to solve parameter uncertainty. The SI is defined as the probability that a location is stable assuming uniform parameter distributions over these uncertainty ranges (Pack et al. 2005).

In the case of $F S_{\min }>1$, namely Probability $(F S>1)=1$, then

$$
S I=F S_{\text {min }}
$$

In the case of $F S_{\min }<=1$, then

$$
S I=\text { Probability }(F S>1)
$$

Table 1 presents the classification rules of slope stability in terms of SI. The slopes in the regions with "Stable", "Moderately stable" and "Quasi-stable" conditions could maintain stability even under worse environmental conditions, and whose instability occurrence would need other significant destabilizing factors. The possibility of slope instability in lower threshold regions and 


\begin{tabular}{|c|c|c|c|}
\hline Condition & Hazard state & Parameter range & $\begin{array}{l}\text { Possible influence of factors not } \\
\text { modeled }\end{array}$ \\
\hline $\mathrm{SI}>1.5$ & Stable & Range cannot model instability & $\begin{array}{l}\text { Significant destabilizing factors are } \\
\text { required for instability }\end{array}$ \\
\hline $1.5>\mathrm{SI}>1.25$ & Moderately stable & Range cannot model instability & $\begin{array}{l}\text { Moderate destabilizing factors are } \\
\text { required for instability }\end{array}$ \\
\hline $1.25>\mathrm{SI}>1.0$ & Quasi-stable & Range cannot model instability & $\begin{array}{l}\text { Minor destabilizing factors are required } \\
\text { for instability }\end{array}$ \\
\hline $1.05>\mathrm{SI}>0.5$ & Lower threshold & $\begin{array}{l}\text { Pessimistic half of range } \\
\text { required for instability }\end{array}$ & $\begin{array}{l}\text { Destabilizing factors are not required for } \\
\text { instability }\end{array}$ \\
\hline $0.5>\mathrm{SI}>0.0$ & Upper threshold & $\begin{array}{l}\text { Optimistic half of range required } \\
\text { for instability }\end{array}$ & $\begin{array}{l}\text { Stabilizing factors may be responsible } \\
\text { for stability }\end{array}$ \\
\hline $\mathrm{SI}=\mathrm{O}$ & Defended & Range cannot model stability & $\begin{array}{l}\text { Stabilizing factors are required for } \\
\text { stability }\end{array}$ \\
\hline
\end{tabular}

Note: "Parameter range" indicates the given range of model parameters for parameter uncertainty.

upper threshold regions is lower and greater than $50 \%$, respectively. Slopes in defended regions will fail to maintain their stability with a significant likelihood under given range of model parameters (Lan et al. 2003; Pack et al. 2005).

\subsection{Modeling procedure and calibration}

Usually, the modeling procedure involves following several steps (Lan et al. 2003; Pack et al. 2005): (1) DEM pit filling corrections; (2) Computation of slope angle and flow direction from DEM; (3) Computation of specific catchment area and saturation index based on hydrological analysis; (4) Computation of FS, SI and slope stability zoning.

Comprehensively considering regional geographical, geological and geomorphological characteristics, the entire study area was divided into 5 individual geological units as shown in Figure 4, which have different susceptibility for landslide occurrences. The initial model parameters were assigned by referring to the Engineering Geology Manual (fourth edition) (Chang and Zhang 2006) and some experiential parameters derived from relative literatures (Pack et al. 1998; Pack et al. 2005; Terhorst and Kreja 2009; Lan et al. 2003; Lan et al. 2004).

The rainfall conditions are taken into account in the model by the parameter of T/q. Due to the significant influence of strong earthquakes on geological settings, it is likely that the accumulated rainfall threshold and the critical hourly rainfall intensity necessary to initiate landslides should be reduced compared with before earthquake (Lin et al. 2004; Lin et al. 2006; Tang et al. 2009; Shieh et al. 2009; He et al. 2011; Zhang et al. 2011). For example, after the Wenchuan earthquake, the accumulated rainfall threshold decreased by $15 \%-$ $22 \%$ and the critical hourly rainfall intensity decreased by $25 \%-32 \%$ for landslide occurrences (Tang et al. 2009; Zhang et al. 2014). After the Chi-

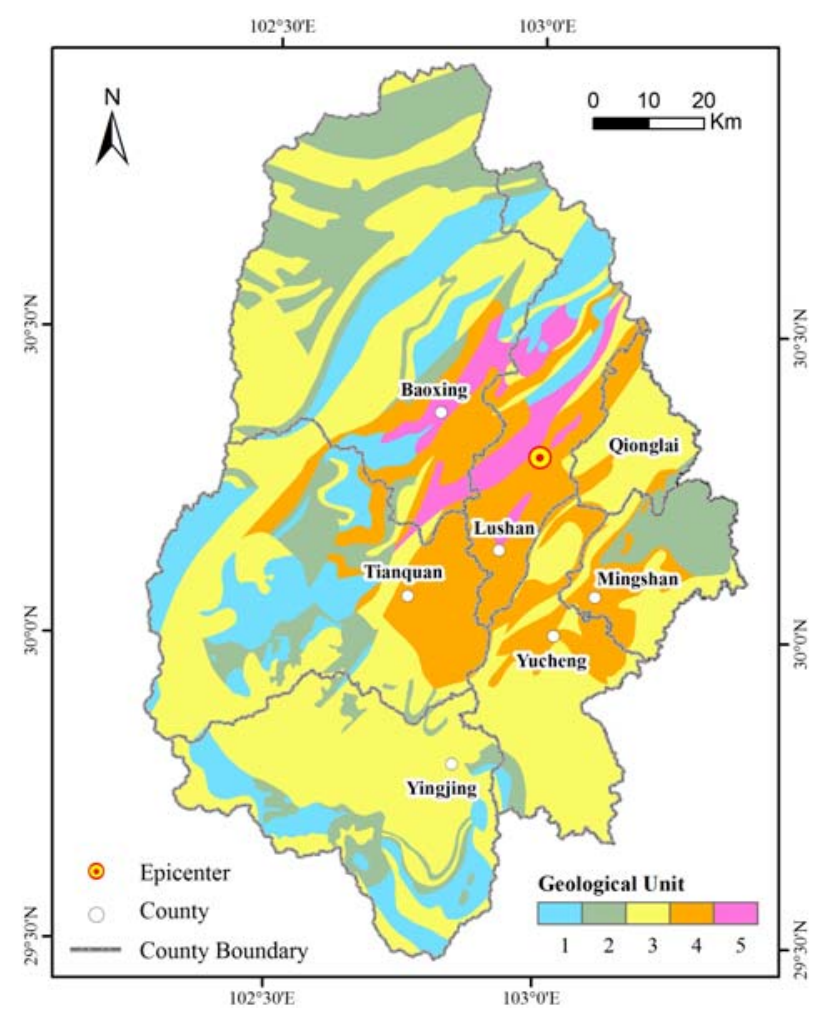

Figure 4 Division of geological units of the study area. Unit 1 is least prone to landslide occurrences, and unit 5 is most prone to landslide occurrences, and unit 2, 3 and 4 are moderately prone to landslide occurrences. 
Chi earthquake, the accumulated rainfall threshold and the critical hourly rainfall intensity decreased to as low as $1 / 3$ of the pre-earthquake figures (Lin et al. 2004). Similarly, considering the significant influence of Lushan earthquake on the geological setting of the study area, we made a rough reduction of initial model parameters by $30 \%$ in terms of previous study results. Then, these model parameters were carefully calibrated using iterative cross-validation between preliminary modeling results and landslide inventory. When the most landslides are distributed in the regions with $\mathrm{SI}<1$, we assume that the model parameters are reasonable and the analytical results are reliable. The detailed description of parameter calibration and validation has been presented in the SINMAP user's manual (Pack et al. 2005).

Table 2 shows the simulated different rainfall conditions. Table 3 shows the final geological parameters for the model. Table 4 shows the final model parameters of $\mathrm{T} / \mathrm{q}$, the original values of which were assigned in terms of different rainfall conditions in the Table 2. It should be pointed out that the parameter $\mathrm{T} / \mathrm{q}_{\max }$ under light rainfall in Table 4 was assigned a value of $10^{6}$, which indicates a significant value during practical calculation. The constant parameters $\gamma_{s}$ and $\gamma_{w}$ were assigned values of $2.0 \times 10^{3} \mathrm{~kg} / \mathrm{m}^{3}$ and $1.0 \times 10^{3} \mathrm{~kg} / \mathrm{m}^{3}$, respectively.

Table 2 Rainfall conditions

\begin{tabular}{lll}
\hline Rainfall (mm) & 24 hours & 12 hours \\
\hline Light rain & $<10.0$ & $<5.0$ \\
Moderate rain & $10.0-24.9$ & $5 \cdot 0-14.9$ \\
Heavy rain & $25.0-49.9$ & $15.0-29.9$ \\
Rainstorm & $50.0-99.9$ & $30.0-69.9$
\end{tabular}

\section{Table 3 Parameters of geological units}

\begin{tabular}{lllll} 
ID (geological units) & $\mathbf{C}_{\min }$ & $\mathbf{C}_{\max }$ & $\boldsymbol{\varphi}_{\min }$ & $\boldsymbol{\varphi}_{\max }$ \\
\hline 1 & 0.14 & 0.36 & 36 & 52 \\
2 & 0.12 & 0.34 & 34 & 50 \\
3 & 0.10 & 0.32 & 32 & 48 \\
4 & 0.06 & 0.27 & 29 & 44 \\
5 & 0.05 & 0.25 & 27 & 42 \\
\hline
\end{tabular}

Note: The ID of geological units corresponds to the number of geological unit legend in Figure 4.

\begin{tabular}{lll}
$\begin{array}{l}\text { Table } 4 \text { Parameter } \\
\text { conditions }\end{array}$ & & \\
Rainfall & $\mathbf{T} / \mathbf{q}_{\min }$ & $\mathbf{T} / \mathbf{q}_{\max }$ \\
\hline Light rainfall & 6600 & $+\infty$ \\
Moderate rainfall & 3400 & 6800 \\
Heavy rainfall & 1800 & 3600 \\
Rainstorm & 1000 & 2000
\end{tabular}

The soil depth was assigned a value of $2-3 \mathrm{~m}$ in terms of the emergent field investigation after Lushan earthquake.

\section{Results and Analysis}

After the above preliminary preparation and analysis, the final slope stability index of the study area was obtained using a final calibrated model with different parameters for different rainfall scenarios (light rainfall, moderate rainfall, heavy rainfall and rainstorm). Then, the slope stability zoning was conducted using the classification rules of slope stability in Table 1 . The entire study area was divided into 6 regions with different slope stabilities: stable region, moderately stable region, quasi-stable region, lower threshold region, upper threshold region and defended region shown in Figure 5 .

Overall, there are obvious spatial differences of slope stability distribution in the study area in spite of different rainfall conditions, which can be reflected by the various colored regions with different slope stability in Figure 5. Although the rainfall is relatively greater in the southeast regions of the study area, the dominant topography is the flat and mild slopes, which are not conducive to landslide occurrences. So, there are not sufficient topographical conditions for landslide initiation and the unstable slope distribution is relatively less frequent in these regions. In the middle and middle-west regions of the study area, there is steep topography, developed valleys and large slope angles. For example, the Baoxing urban area is located in a narrow valley area with many high and steep mountains on both sides. In these regions, the rainfall is relatively less, but the complex topography predicts high landslide susceptibility and a low rainfall threshold. So, the unstable slope distribution is relatively extensive, which indicates a high rainfall-triggered landslide hazard level.

The slope stability distribution under different rainfall conditions is strongly correlated with earthquake intensity distribution. The unstable slopes are mainly distributed in the northwest of the regions with an earthquake intensity of 7-9 degrees. Although the southeast of the regions with earthquake intensity of 7-9 degrees also suffered strong earthquake effects, for example the 


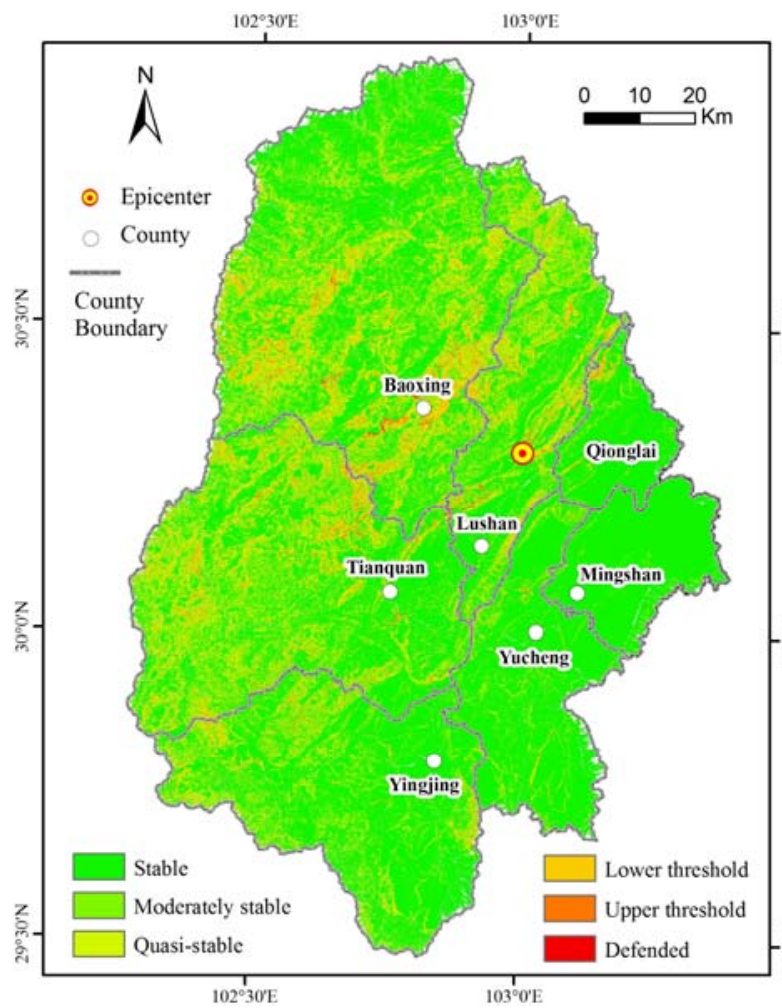

(a)

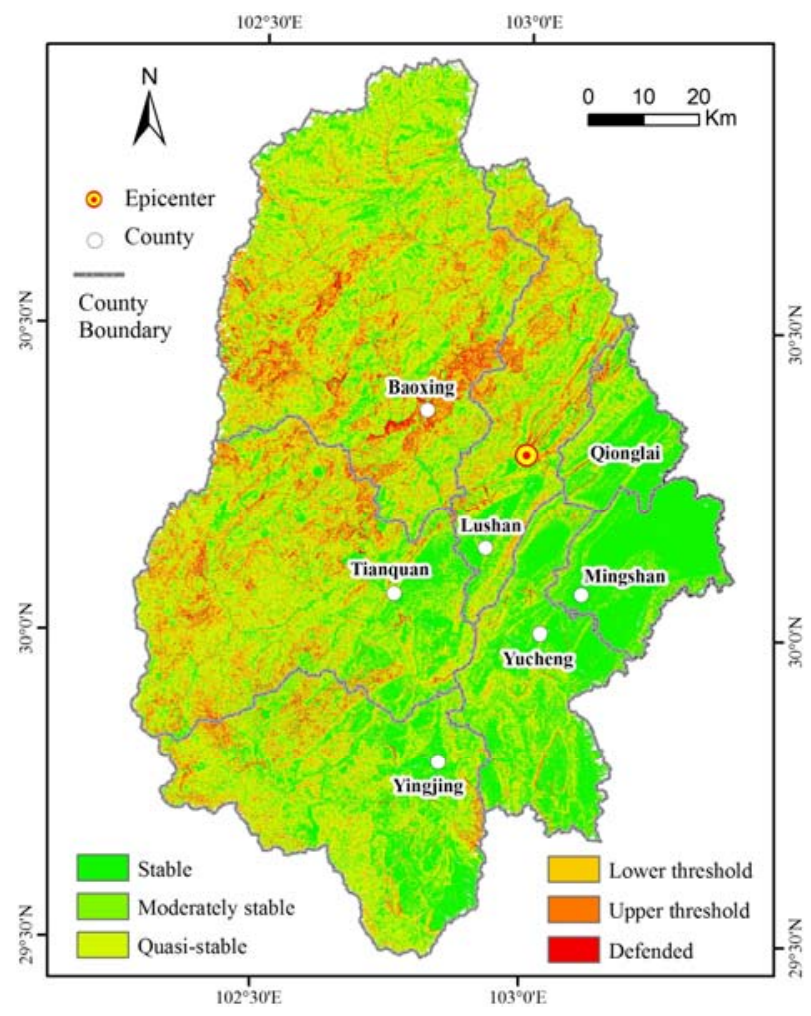

(c)

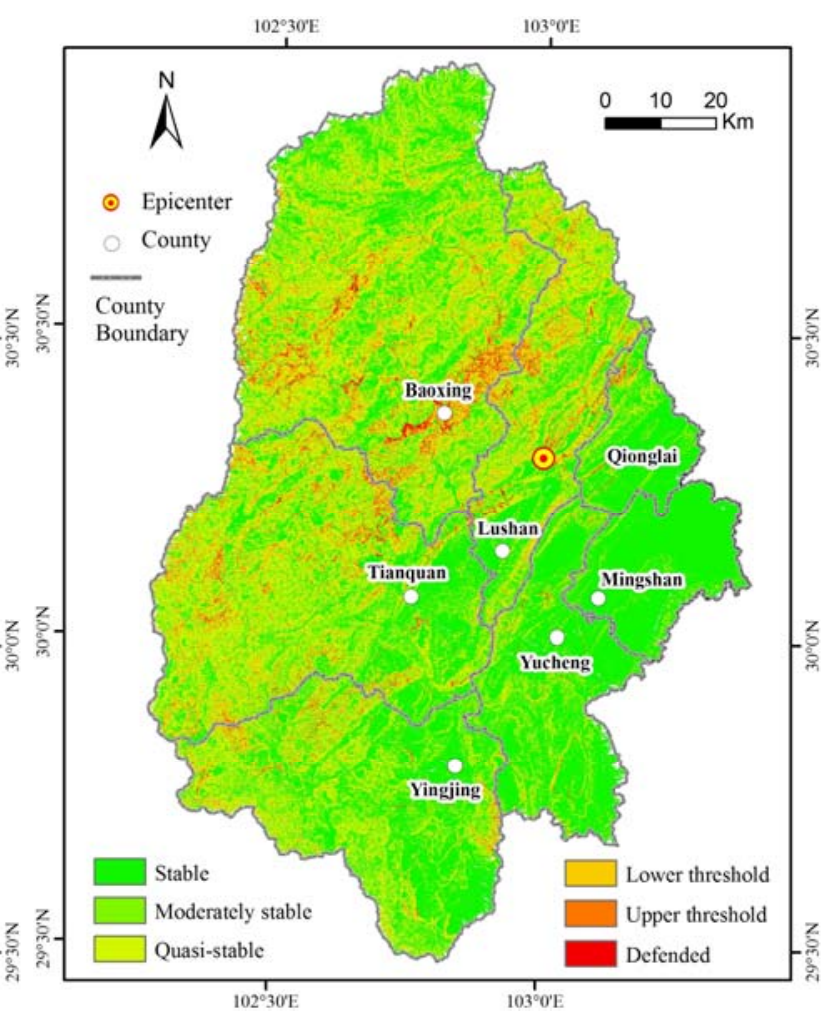

(b)

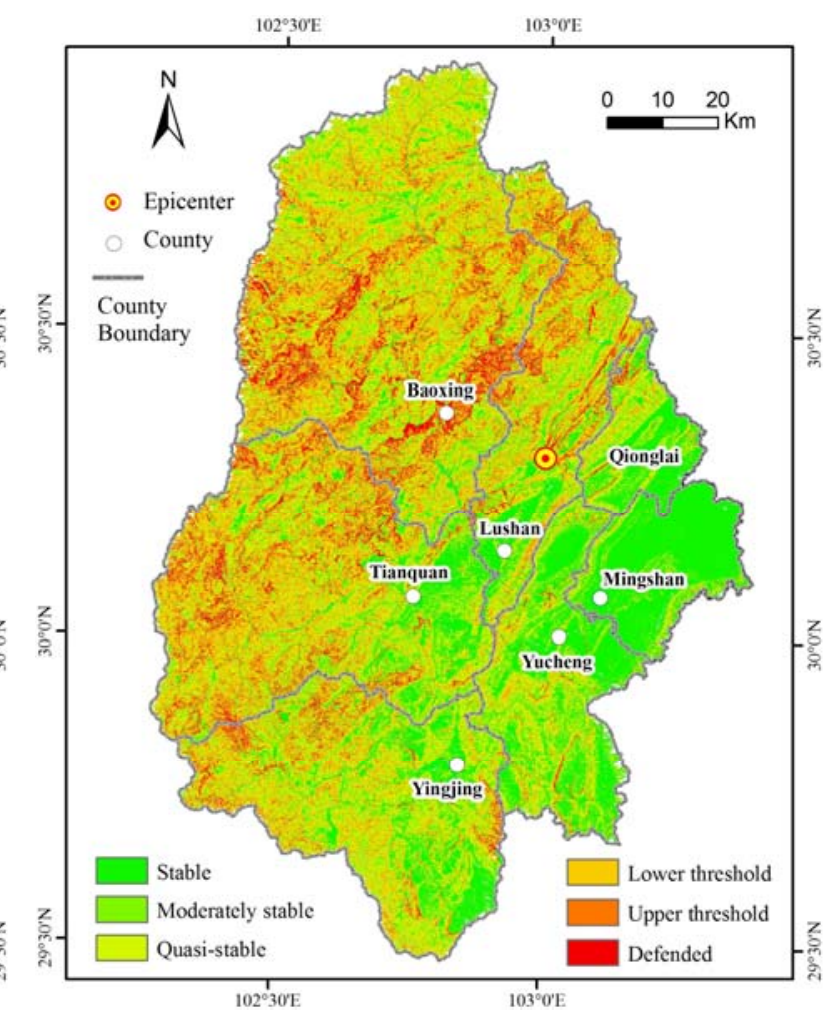

(d)

Figure 5 Slope stability distribution maps under different rainfall conditions. (a) Light rainfall, (b) Moderate rainfall, (c) Heavy rainfall, (d) Rainstorm. 
abundance of destroyed infrastructure, the dominant topography with flat and mild slopes is not conducive to landslide occurrences and the distribution of unstable slopes is not extensive.

Rainfall infiltrates hillsides and becomes groundwater that can increase the saturation of shallow slopes, and decrease rock mass strength and stabilizing force, which should cause slope instability and increase the likelihood of landslide occurrences (Wu et al. 2011). In the regions near mountain ridges where groundwater diverges, slopes have smaller specific catchment areas and their instability needs a higher slope angle and more intense rainfall to trigger. However, in the regions near valley where groundwater converges, the slopes have larger specific catchment areas and their instability needs a lower slope angle and less rainfall.

In order to further analyze the detailed characteristics of the rainfall-triggered landslide distribution, we got the area of various regions with different slope stabilities under different rainfall conditions, whose proportion and variation patterns are shown in Figure 6. The area variation between various slope stability regions obviously reflects the significant influence of rainfall on slope stability in the study area. With the gradual increase of rainfall, the area and proportion of stable regions decreased remarkably, while the area and proportion of unstable regions increased remarkably. The area of stable and moderately stable regions decreased from $77.2 \%$ under light rainfall to $27.4 \%$ under rainstorm. Meanwhile, the area of upper threshold and defended regions increased from $0.9 \%$ under light rainfall to $15.1 \%$ under rainstorm. The area of regions that transition from stable regions to unstable regions,

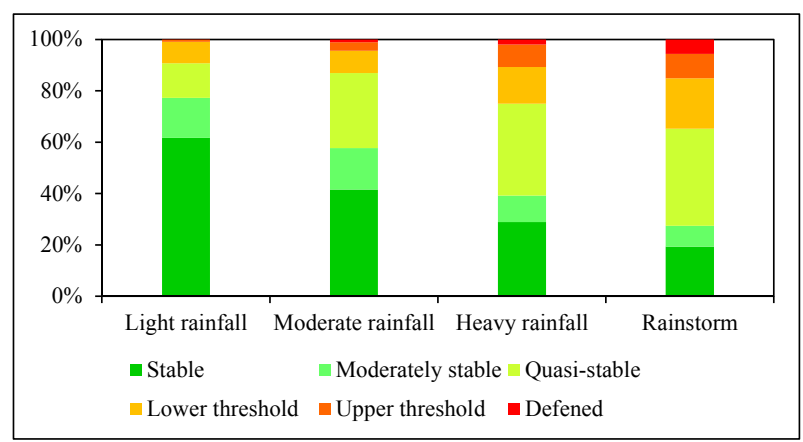

Figure 6 The percentage of area of different lands having different degree of slope stability under different rainfall conditions. including quasi-stable and lower threshold regions, has relatively little increase from $21.9 \%$ under light rainfall to $57.5 \%$ under rainstorm, which mainly occurs during the transitional stage from light rainfall to moderate rainfall.

The Lushan earthquake had an adverse influence on geological settings and triggered a large amount of rock avalanches in earthquakeaffected regions, which resulted in abundant loose deposits and sediments. These deposits and sediments on hillsides provide crucial material for subsequent rainfall-triggered landslides and debris flows. So, the geological setting will be more conducive to landslide occurrences and the rainfall threshold of triggering landslides decreased to some extent in the study area after the Lushan earthquake. It can be predicted that the landslide frequency and intensity will be relatively higher for a period of time after earthquake than before earthquake under the same rainfall conditions.

\section{Discussions and Conclusions}

The detailed co-seismic landslide inventory was acquired through post-earthquake emergent field investigation and high resolution remote sensing interpretation. The secondary geological hazards induced by Lushan earthquake are dominated by shallow landslides. The distribution of co-seismic geological hazards has high relationship with the distribution of earthquake intensity while the pre-earthquake distribution is correlated with the characteristics of geomorphology.

In addition, the resultant abundant loose materials are prone to post-earthquake landslides especially under different rainfall conditions. The rainfall analysis is conducted using historical rainfall records during the period from 1951 to 2010. Results reveal the heterogeneous characteristics of spatial distribution of rainfall. The post-earthquake slope stability under different rainfall conditions is evaluated by the Stability Index MAPping (SINMAP) model which is suitable for shallow slope stability analysis. The model parameters were calibrated to reflect the significant influence of strong earthquakes on geological setting and the effect of different rainfall conditions on hydraulic parameters. The slope stability maps 
triggered by different rainfall scenarios are produced at a regional scale. The expanding trend of the unstable area was quantitatively assessed with the gradual increase of critical rainfall intensity. They provide a new insight into the spatial distribution and characteristics of postearthquake rainfall-triggered landslides in the Lushan seismic area.

There is evidence of a correlation between slope stability and rainfall. With the increase of rainfall, the unstable regions increase significantly. Strong earthquakes can seriously affect geological conditions and result in the decrease of the rainfall threshold of triggering landslides to some extent. Under the same rainfall conditions, the landslide frequency and intensity will be higher for a period of time after an earthquake than before the earthquake until the absolute disappearance of the earthquake effect. The heterogeneous distribution of landslides is highly relative to the distribution of earthquake intensity in spite of different rainfall conditions. The results suggest that the both seismic intensity and rainfall are two crucial factors for post-earthquake landslide assessment.

It should be noted that the uncertainty of modeling should be taken into account for the interpretation of modeling results. Some elements, such as DEM resolution, the completion of a landslide inventory, rainfall process and properties of rock masses have high impact on the uncertainty of the slope stability distribution map. In our study, the geological conditions are significantly affected by the Lushan earthquake and it is sometimes

\section{References}

Aleotti P, Chowdhury R (1999) Landslide hazard assessment: summary review and new perspectives. Bulletin of Engineering Geology and the Environment 58: 21-44. DOI: 10.1007/s100640050066

Baum RL, Godt JW, Savage WZ (2010) Estimating the timing and location of shallow rainfall-induced landslides using a model for transient, unsaturated infiltration. Journal of Geophysical Research 115: Fo3013. DOI: 10.1029/2009JFoo1321

Chang SB, Zhang SM (2006) Engineering Geology Manual (fourth edition). Beijing: China Architecture and Building Press. (In Chinese)

Chen XQ, Cui P, You Y, et al. (2013) Secondary mountain disasters induced by the 4.20 Lushan earthquake and disaster mitigation. Earth Science Frontiers 20: 29-34. (In Chinese)

China Earthquake Administration. http://www.cea.gov.cn/ publish/dizhenj/468/553/100342/index.html, 2013-4-23. (In Chinese)

Cui P, Wei FQ, He SM, et al. (2008) Mountain Disasters difficult to determine precise parameters of modeling geological units, which results in high uncertainty. The presented assessment results of rainfall-triggered slope stability in the current study are only suitable for a certain period after an earthquake. With the gradual decrease of the earthquake effect, the environmental factors that significantly affect landslide occurrences will gradually recover to the condition prior to earthquake. The assessment on rainfall-triggered slope stability should be adjusted appropriately to adapt for variable environmental factors for the different periods after earthquake. Nevertheless, this study provides important references for landslide prevention and mitigation in the Lushan area after the earthquake.

\section{Acknowledgement}

This research was supported by the Project of the 12th Five-year National Sci-Tech Support Plan of China (2011BAK12Bo9) and the National Science Foundation of China (41072241) and the One Hundred Talents Program of Chinese Academy of Sciences (A1055) and the China Geological Survey Project (12120113038000). The authors also wish to acknowledge the Chengdu University of Technology for providing geological hazard data and the China Centre for Resources Satellite Data and Application for providing remote sensing data.
Induced by the Earthquake of May 12 in Wenchuan and the Disasters Mitigation. Journal of Mountain Science 26: 280282. (In Chinese)

Deb SK, El-Kadi AI (2009) Susceptibility assessment of shallow landslides on Oahu, Hawaii, under extreme-rainfall events. Geomorphology 108: 219-233. DOI: 10.1016/j.geomorph. 2009.01.009

Dietrich WE, Reiss R, Hsu ML, et al. (1995) A process-based model for colluvial soil depth and shallow landsliding using digital elevation data. Hydrological Processes 9: 383-400. DOI: 10.1002/hyp.3360090311

Guzzetti F, Carrara A, Cardinali M, et al. (1999) Landslide hazard evaluation: a review of current techniques and their application in a multi-scale study, Central Italy. Geomorphology 31: 181-216. DOI: 10.1016/So169-555X(99) 00078-1

He SM, Li DX, Wu Y, et al. (2011) Study on the Rainfall and Aftershock Threshold for Debris Flow of Post-earthquake. 
Journal of Mountain Science 8: 750-756. DOI: 10.1007/ s11629-011-2046-2

Lan HX, Zhou CH, Wang LJ, et al. (2004) Landslide hazard spatial analysis and prediction using GIS in the Xiaojiang watershed, Yunnan, China. Engineering Geology 76: 109-128. DOI: 10.1016/j.enggeo.2004.06.009

Lan HX, Wu FQ, Zhou CH, et al. (2003) Spatial hazard analysis and prediction on rainfall-induced landslide using GIS. Chinese Science Bulletin 48: 703-708. DOI: 10.1007/ BFo3325659

Liang QG, Han WF, Li XF (2009) Discussion on seismic failure of rock mass in meizoseismal areas. Rock and Soil Mechanics 30(supplement): 37-40. (In Chinese)

Lin CW, Shieh CL, Yuan BD, et al. (2004) Impact of Chi-Chi earthquake on the occurrence of landslides and debris flows: example from the Chenyulan River watershed, Nantou, Taiwan. Engineering Geology 71: 49-61. DOI: 10.1016/Soo137952(03)00125-X

Lin CW, Liu SH, Lee SY, et al. (2006) Impacts of the Chi-Chi earthquake on subsequent rainfall-induced landslides in central Taiwan. Engineering Geology 86: 87-101. DOI: 10.1016/j.enggeo.2006.02.010

Meisina C, Scarabelli S (2007) A comparative analysis of terrain stability models for predicting shallow landslides in colluvial soils. Geomorphology 87: 207-223. DOI:10.1016/j. geomorph.2006.03.039

Miles SB, Keefer DK (2009) Toward a comprehensive areal model of earthquake-induced landslides. Natural Hazards Review 10: 19-28. DOI: 10.1061/(ASCE)1527-6988(2009) 10:1(19)

Montgomery DR, Dietrich WE (1994) A physically based model for the topographic control on shallow landsliding. Water Resources Research 30: 1153-1171. DOI: 10.1029/93WR02979

Muntohar AS, Liao HJ (2010) Rainfall infiltration: infinite slope model for landslides triggering by rainstorm. Natural Hazards 54: 967-984. DOI: 10.1007/s11069-010-9518-5

Pack RT, Tarboton DG, Goodwin CN (1998) The SINMAP approach to terrain stability mapping. In: Moore D, Hungr O, Proceedings of eighth international congress international association for engineering geology and the environment. Vancouver, Canada. pp 1157-1165

Pack RT, Tarboton DG, Goodwin CN (2005) A stability index approach to terrain stability hazard mapping. SINMAP user's manual.

Schulz WH, McKenna JP, Kibler JD (2009) Relations between hydrology and velocity of a continuously moving landslide evidence of pore-pressure feedback regulating landslide motion. Landslides 6: 181-190. DOI: 10.1007/s10346-0090157-4

Shieh CL, Chen YS, Tsai YJ, et al. (2009) Variability in rainfall threshold for debris flow after the Chi-Chi earthquake in central Taiwan, China. International Journal of Sediment Research 24: 177-188. DOI: 10.1016/S1001-6279(09)60025-1

Simoni A, Berti M, Generali M (2004) Preliminary result from pore pressure monitoring on an unstable clay slope. Engineering Geology 73: 117-128. DOI: 10.1016/j.enggeo. 2003.12.004

Tang C, Zhu J, Li WL, et al. (2009) Rainfall-triggered debris flows following the Wenchuan earthquake. Bulletin of Engineering Geology and the Environment 68: 187-194. DOI: 10.1007/s10064-009-0201-6

Terhorst B, Kreja R (2009) Slope stability modelling with SINMAP in a settlement area of the Swabian Alb. Landslides 6: 309-319. DOI: 10.1007/s10346-009-0167-2

Vidrih R, Ribičič M, Suhadolc P (2001) Seismogeological effects on rocks during the 12 April 1998 upper Soča Territory earthquake (NW Slovenia). Tectonophysics 330: 153-175. DOI: 10.1016/Soo40-1951(oo)00219-5

Wu Y, He SM, Luo Y, et al. (2011) Failure Mechanisms of PostEarthquake Bedrock Landslides in Response to Rainfall Infiltration. Journal of Mountain Science 8: 96-102. DOI: 10.1007/s11629-011-2074-y

Xu XW, Chen GH, Yu GH, et al. (2013) Seismogenic structure of the Lushan earthquake and its relationship with The Wenchuan earthquake. Earth Science Frontiers 20: 11-20. (In Chinese)

Zhang Y, Cheng YL, Li CS, et al. (2011) Comparatives study on geological disasters before and after Wenchuan earthquake. Journal of Engineering Geology 19(supplement): 179-185. (In Chinese)

Zhang YS, Dong SW, Hou CT, et al. (2013) Geohazards induced by the Lushan Ms7.o earthquake in Sichuan Province, Southwest China: typical examples, types and distributional characteristics. Acta Geologica Sinica (English Edition) 87: 646-657. DOI: $10.1111 / 1755-6724.12076$

Zhang YS, Cheng YL, Yin YP, et al. (2014) High-position debris flow: a long-term active geohazard after the Wenchuan earthquake. Engineering Geology 180: 45-54. DOI: 10.1016/ j.enggeo.2014.05.014 